\title{
Determination of pro-oxidant-antioxidant balance (PAB) assay in mothers with spontaneous abortion
}

Faezeh Ghasemi ${ }^{1}$, Alireza Kamali², Maryam Shokrpour ${ }^{3^{*}}$

DOI. 10.21931/RB/2021.06.03.14

Abstract: Oxidative stress has been identified to play a vital role in the pathogenesis of spontaneous abortion were characterized as an imbalance between the generation of pro-oxidants, free radicals, and reactive species, and enzymatic and non-enzymatic antioxidant defenses in favor of the former. In the present study, the pro-oxidant-antioxidant balance was assessed in women with spontaneous abortion and compared with healthy age-matched controls. A group of 50 females with spontaneous abortion were considered patients, and a group of age-matched healthy pregnant women was considered controls. The pro-oxidantantioxidant balance (PAB) assay was carried out on participants' serum samples. The mean age of the spontaneous abortion group was $30.84 \pm 3.82$, and controls were $26.53 \pm 4.05$ years. The obtained PAB values were $236.74 \pm 11.37 \mathrm{HK}$ and 148.69 $\pm 76.50 \mathrm{HK}$ in patients and controls. Our results demonstrate the significant rise of PAB values in subjects with spontaneous abortion compared to healthy controls $(p<0.0001)$. Our study showed that the PAB values might be involved in the termination of spontaneous abortion.

Key words: Spontaneous abortion, Oxidative stress, Antioxidants, PAB assay.

\section{Introduction}

Spontaneous abortion is considered as the fetus's natural death before 20 gestations. Based on scientific declarations, spontaneous abortion defines by pregnancy termination before complete 20 weeks gestational period while the fetal weight is less than a half kilogram ${ }^{1,2}$. Massive investigation showed that the rate of spontaneous abortion depends on pregnancy age and miscarriage ${ }^{3,4}$. According to the Cardone et al. rate of spontaneous abortion increased in elder females compare with younger cases. In North American pregnant females, spontaneous abortion happened in $17 \%$ - $20 \%$ cases younger than 25 years old whereas increased to 30\%-35\% in those with 35-45 years old ${ }^{3}$.

Cramer and Wise published data demonstrated that miscarriage increase spontaneous abortion risk. The incidence of spontaneous abortion in females with no miscarriage is approximately 13 percent and increased to 25\%, $30 \%$, and 35 $\%$ in those who suffered from 1,2 , and 3 miscarriages, respectively ${ }^{3}$. Further investigation illustrated the various spontaneous abortion risk factors. Dickey RP and colleagues represented the higher incidence of spontaneous abortion in one-fourth of females treated with human gonadotropin and clomiphene ${ }^{5}$.

Moreover, fragmentation of sperm DNA, hyperhomocysteinemia, immunological disorders, and insufficient antioxidant defenses have also been observed in females with spontaneous abortion 4 .

Oxidative stress, a profound imbalance between pro-oxidants, reactive oxygen specious, free radicals, and enzymatic and non-enzymatic antioxidants in favor of the former, plays the leading role in disorders and deficiencies ${ }^{6,7}$. Despite the essential role of oxygen in metabolism and life persistency, its toxic derivatives can be caused severe damage to cellular compartments ${ }^{7}$.

Reactive species damage DNA, mitochondria, and cell membrane, which affects the cellular compartments pathologically and leads to ultimate cellular demise ${ }^{8,9}$. In response to oxidative damage, the antioxidant system neutralizes the excess pro-oxidants, maintains physiological balance, and establishes cellular homeostasis ${ }^{10,11}$. Simsek et al. uncovered the essential role of oxidative damage, higher level of lipid peroxidation, and reactive oxygen specious immediately before abortion ${ }^{12,13}$

Although the exact causes of spontaneous abortion are not clearly understood, immunological alterations and profound disruption of oxidative stress seem to be involved etiologically. Our study aims to characterize the prooxidant-antioxidant balance $(\mathrm{PAB})$ in patients with spontaneous abortion.

\section{Materials and methods}

\section{Subjects}

The presented study was conducted on 80 pregnant females (50 with spontaneous abortion history as a patient group and 30 normal age-matched healthy women without a history of abortion as controls) hospitalized between March 2017 and October 2018 in Taleghani Hospital Arak, Iran. The first day of gestation was determined based on ultrasound obtained data, and obstetricians evaluated the risk of spontaneous abortion in participants. Females who had been exposed to teratogenic drugs were excluded, whereas the participants who have had at least 1 terminated abortion before complete 20 weeks gestation were categorized as the patients. Moreover, all participants were signed the written consent to contribute to the survey that the ethics committee approved of Arak Medical School.

\section{Sample collection}

For all subjects, the age, history of spontaneous abortion, gestational time, deliveries, and abortions were recorded. To carrying out the PAB assay, $2 \mathrm{ml}$ arterial-venous mixed cord

\footnotetext{
${ }^{1}$ Blood Transfusion Research Center, High Institute for Research and Education in Transfusion Medicine, Next to Milad Tower, Tehran, Iran.

${ }^{2}$ Departments of Anesthesiology and Critical Care, Arak University of Medical Sciences, Arak, Iran.

Department of Gynecology, Faculty of Medicine, Arak University of Medical Sciences, Arak, Iran
} 
blood was collected after delivery and abortion. The collected blood samples were centrifuged at 3600 rpm for 10 minutes after clotting to separate sera. To measure the oxidative stress parameters in the rapid, accurate method, the obtained sera were kept at $-80^{\circ} \mathrm{C}$ until analysis. The hemolytic samples were excluded from the PAB assay.

\section{Chemicals}

The chemicals were used in our survey include TMB pow$\operatorname{der}\left(3,3^{\prime}, 5,5^{\prime}\right.$-Tetramethylbenzidine, Fluka), chloramine T trihydrate (AppliChem: A4331, Darmstadt, Germany), peroxidase enzyme (AppliChem: 230 U/mg, A3791, 0005, Darmstadt, Germany), hydrogen peroxide (Merck). Double distilled water was applied for dissolving molecular biology grade reagents that need further preparation.

\section{The pro-oxidant antioxidant balance (PAB) assay}

PAB assay was carried out based on our previous studies $^{14,15}$. Standard solutions were prepared by blending the exact proportion of $250 \mathrm{M} \mathrm{H} 2 \mathrm{O} 2(0-100 \%)$ and uric acid $3 \mathrm{mM}$ and added to the $\mathrm{NaOH}(10 \mathrm{mM})$. To prepare TMB cation, 60 mg TMB powder was dissolved in $10 \mathrm{ml}$ dimethyl sulfoxide (DMSO) and was added to $20 \mathrm{ml}$ acetate buffer (0.05 M, pH 4.5). After that, well-mixed $70 \mu \mathrm{l}$ freshly chloramine $\mathrm{T}$ solution $(100 \mathrm{mM})$ was added to the previously prepared solution, shacked immediately, and incubated for 2 hours at room temperature $\left(23^{\circ} \mathrm{C}-27^{\circ} \mathrm{C}\right)$ in the dark places.

The horseradish peroxidase working solution was prepared by blending the 25-unit peroxidase enzyme solution into the $20 \mathrm{ml}$ TMB cation and aliquoted into $1 \mathrm{ml}$ microtubes and stored at -20 , respectively. TMB working solution was prepared by gently blending $200 \mu \mathrm{LMB} / \mathrm{DMSO}$ into the $10 \mathrm{ml}$ acetate buffer (0.05 M, pH 5.8).

To determine the PAB values in the subjects' sample, 200 $\mu \mathrm{l}$ working solution was added to each well of 96-well ELISA. Then, $10 \mu \mathrm{l}$ participants' sera, distilled $\mathrm{H}_{2} \mathrm{O}$ (blank well), and standard solutions were added and mixed gently as well as the plates were incubated in the dark place at $37^{\circ} \mathrm{C}$ for 15 minutes. The $50 \mu \mathrm{l}$ of $2 \mathrm{~N} \mathrm{HCl}$ was recruited as the stop solution, and the PAB was measured at $450 \mathrm{~nm}$ wavelength.

The PAB values were demonstrated in arbitrary HK units, the percentage of $\mathrm{H}_{2} \mathrm{O}_{2}$ in the standard solution. Meanwhile, unknown samples were then calculated based on the obtained values from the standard drowning curve.

\section{Statistical analysis}

The Statistical Package for Social Sciences (SPSS version 20.0, IBM, USA) was used for data analysis while the P-value $<0.05$ was considered statistically significant. The Kolmogorov-Smirnov test was carried out to determine the data's normality, and unpaired sample T-tests were applied for evaluating the statistical analysis.

\section{Results}

The mean age of participants with spontaneous abortion and controls were $30.84 \pm 3.82$ and $26.53 \pm 4.05$ years, respectively. The higher range and lower range of participants' PAB value shows $214-253.74 \mathrm{HK}$ in females with spontaneous abortion and $2.50-264.03$ in the standard group. Our obtained data revealed a significantly raised level of PAB values in spontaneous abortion participants compared to the standard group ( $p$-value $<0.0001$ ) (figure 1 ).

No abortion was seen in controls, while in the spontaneous abortion group, 21 cases had had one abortion, and 5 cases had had 3 abortions. Furthermore, 29 cases had delivered at least one normal childbirth (Table 1).

\section{Discussion}

Massive investigations demonstrate the role of oxidative stress in the pathogenesis of spontaneous abortion, pre-eclamptic pregnancy, and related pregnancy hypertensive

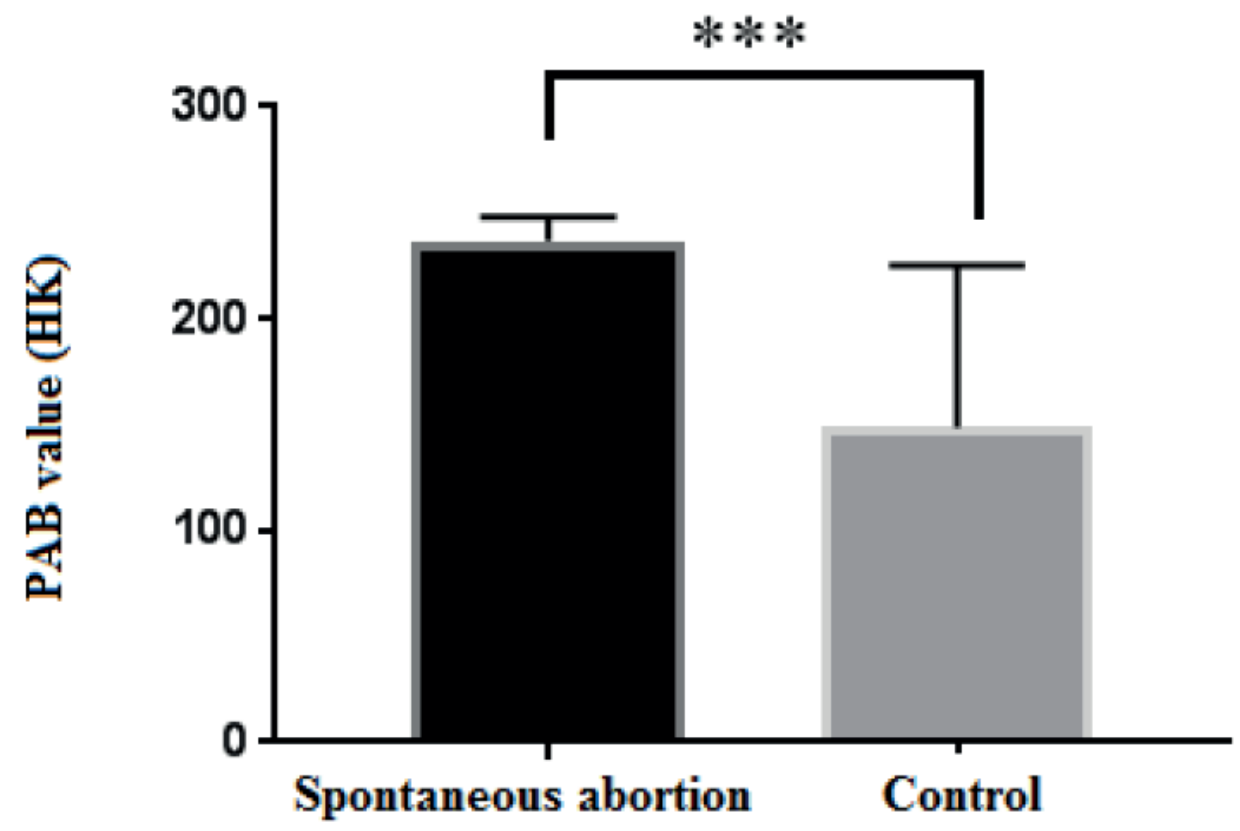

Figure 1. Evaluation of the PAB values between two groups. Results showed a significant increase in PAB values in the spontaneous abortion group 236.74 $\pm 11.37 \mathrm{HK}$ compared to the control group $148.69 \pm 76.50(p<0.0001)$. 


\begin{tabular}{|c|c|c|c|c|c|c|}
\hline \multicolumn{2}{|c|}{ Delivery-abortion /Group } & Frequency & Mean & S.D & Max & Min \\
\hline \multirow{2}{*}{ Delivery } & Spontaneous abortion & 50 & 2.76 & 0.77 & 5 & 2 \\
\cline { 2 - 6 } & control & 30 & 1.03 & 0.18 & 2 & 1 \\
\hline \multirow{2}{*}{ abortion } & Spontaneous abortion & 50 & 1.7 & 0.73 & 4 & 1 \\
\cline { 2 - 6 } & control & 30 & 0 & 0 & 0 & 0 \\
\hline \multirow{2}{*}{$\begin{array}{c}\text { Gestation } \\
\text { (week) }\end{array}$} & Spontaneous abortion & 50 & 26.54 & 11.10 & 40 & 6 \\
\cline { 2 - 7 } & control & 30 & 38.06 & 2.86 & 41 & 28 \\
\hline
\end{tabular}

Table 1. Comparison the delivery, abortion and gestational time between spontaneous abortion group and controls.

disorders ${ }^{16-18}$. Higher levels of oxidants such as malondialdehyde, protein carbonyl, erythrocyte glutathione peroxidase, and erythrocyte superoxide dismutase were observed in placentation, miscarriage, and recurrent pregnancy $\operatorname{loss}^{19}$. Our results indicate that a significant increase in pro-oxidants in subjects with spontaneous abortion compared to controls.

Despite the suggestion of published reports that show the beneficial effects of antioxidants in vitro fertilization (IVF), rare of them demonstrate the role of antioxidants in miscarriage ${ }^{20,21}$. Recent investigations demonstrate that the proper fetus implantation seriously depends on low oxygen concentration to complete 10 gestational weeks ${ }^{22}$. It may protect fetal development and differentiation against reactive specious, free radicals, and immunological reactions ${ }^{19}$. Compelling evidence uncovered the deficient trophoblastic invasion that occurred following the spontaneous abortions ${ }^{23}$. Therefore, in the same direction as our obtained data, oxidative stress may raise the spontaneous abortions before complete 10 weeks of gestation, which might be the consequence of maternal bloodflow disorders ${ }^{19}$.

Higher lipid peroxidation and oxidative stress biomarkers such as malondialdehyde increase in females with spontaneous abortion ${ }^{24}$. Sugino et al. published a report that showed the higher concentration of lipid peroxidation in females with spontaneous abortion suffered from vaginal bleeding ${ }^{25}$. These observations boost our hypothesis about the role of oxidative stress in spontaneous abortion. In other words, higher levels of reactive specious, free radicals and consequent oxidative damages lead to placenta oxidation, spontaneous abortion, and fetal termination. A higher level of lipid peroxides such as malondialdehyde may involve in urine evacuation.

The corpus luteum activity is fundamental for embryogenesis and fetal development. The early stages of pregnancy and trophoblast implantation are dependent on corpus luteum activity which relies upon superoxide dehydrogenase-enzyme activity. In the ovary, superoxide dehydrogenase prevents the restrictive reaction of hydrogen peroxide-derived peroxide and superoxide ions on gonadotropin hormones and affects the ovary's follicular function ${ }^{26}$, demonstrating the role of superoxide dehydrogenase-enzyme activity in early gestation.

Interestingly, Umaoka and colleagues demonstrate that in vitro fetal development was restricted during the high level of oxygen. Likewise, reactive oxygen specious and superoxide ions cause severe damage to embryogenesis and trophoblast expansion. Superoxide dehydrogenase can prevent the harmful effects of superoxide ions ${ }^{27}$.

\section{Conclusions}

A significant increase in pro-oxidants and oxidative stress were reported in several investigations. Based on our data, profound disruption of oxidative stress may involve spontaneous abortion even though more surveys are needed.

\section{Bibliographic references}

1. Kwegyir-Afful E, Adu G, Spelten ER, Räsänen K, Verbeek J. Maternity leave duration and adverse pregnancy outcomes: An international country-level comparison. Scandinavian journal of public health. 2018; 46(8): 798-804.

2. Blencowe $H$, Cousens S, Oestergaard MZ, Chou D, Moller A-B, Narwal R, et al. National, regional, and worldwide estimates of preterm birth rates in 2010 with time trends since 1990 for selected countries: a systematic analysis and implications. The lancet. 2012; 379(9832): 2162-72.

3. Gupta S, Agarwal A, Banerjee J, Alvarez JG. The role of oxidative stress in spontaneous abortion and recurrent pregnancy loss: a systematic review. Obstetrical \& gynecological survey. 2007; 62(5): 335-47.

4. Cramer DW, Wise LA. The epidemiology of recurrent pregnancy loss. Seminars in reproductive medicine 2000; 18(04): 331-40.

5. Dickey RP, Taylor SN, Curole DN, Rye PH, Pyrzak R. Infertility: Incidence of spontaneous abortion in clomiphene pregnancies. Human reproduction. 1996; 11(12): 2623-28.

6. Pouya VT, Hashemy SI, Shoeibi A, Tirkani AN, Tavallaie S, Avval FZ, et al. Serum Pro-Oxidant-Antioxidant Balance, Advanced Oxidized Protein Products (AOPP) and Protein Carbonyl in Patients With Stroke. Razavi International Journal of Medicine. 2016; 4(2):

7. Avval FZ, Mahmoudi N, Tirkani AN, Jarahi L, Alamdari DH, Sadjadi SA. Determining Pro-Oxidant Antioxidant Balance (PAB) and Total Antioxidant Capacity (TAC) in Patients with Schizophrenia. Iranian journal of psychiatry. 2018; 13(3): 222.

8. Sharif ME, Mohamedain A, Ahmed AA, Nasr AM, Adam I. Folic acid level and preterm birth among Sudanese women. Maternal health, neonatology and perinatology. 2017; 3(1): 25.

9. Ronnenberg AG, Goldman MB, Chen D, Aitken IW, Willett WC, Selhub J, et al. Preconception folate and vitamin B6 status and clinical spontaneous abortion in Chinese women. Obstetrics \& Gynecology. 2002; 100(1): 107-13.

10. Agarwal A, Allamaneni SS. Role of free radicals in female reproductive diseases and assisted reproduction. Reproductive biomedicine online. 2004; 9(3): 338-47.

11. Lu J, Wang Z, Cao J, Chen Y, Dong Y. A novel and compact review on the role of oxidative stress in female reproduction. Reproductive Biology and Endocrinology. 2018; 16(1): 80. 
12. Şimşek $M$, Naziro®lu M, Şimşek H, Cay M, Aksakal M, Kumru S. Blood plasma levels of lipoperoxides, glutathione peroxidase, beta carotene, vitamin $\mathrm{A}$ and $\mathrm{E}$ in women with habitual abortion. Cell Biochemistry and Function: Cellular biochemistry and its modulation by active agents or disease. 1998; 16(4): 227-31.

13. Mohd Mutalip S, Ab-Rahim S, Rajikin M. Vitamin E as an antioxidant in female reproductive health. Antioxidants. 2018; 7(2): 22.

14. Pouya VT, Hashemy SI, Shoeibi A, Tirkani AN, Tavallaie S, Avval FZ, et al. Serum Pro-Oxidant-Antioxidant Balance, Advanced Oxidized Protein Products (AOPP) and Protein Carbonyl in Patients With Stroke. Razavi International Journal of Medicine. 2016; 4(2):

15. Alamdari DH, Ghayour-Mobarhan M, Tavallaie S, Parizadeh MR, Moohebati M, Ghafoori F, et al. Prooxidant-antioxidant balance as a new risk factor in patients with angiographically defined coronary artery disease. Clinical biochemistry. 2008; 41(6): 375-80.

16. Vanderlelie J, Venardos K, Clifton V, Gude N, Clarke F, Perkins A. Increased biological oxidation and reduced antioxidant enzyme activity in pre-eclamptic placentae. Placenta. 2005; 26(1): 53-58.

17. Scholl TO, Leskiw M, Chen X, Sims M, Stein TP. Oxidative stress, diet, and the etiology of preeclampsia. The American journal of clinical nutrition. 2005; 81(6): 1390-96.

18. Bulgan Kilicdag E, Ay G, Celik A, Ustundag B, Ozercan I, Simsek M. Oxidant-antioxidant system changes relative to placental-umbilical pathology in patients with preeclampsia. Hypertension in pregnancy. 2005; 24(2): 147-57.

19. Ozkaya O, Sezik M, Kaya H. Serum malondialdehyde, erythrocyte glutathione peroxidase, and erythrocyte superoxide dismutase levels in women with early spontaneous abortions accompanied by vaginal bleeding. Medical Science Monitor. 2008; 14(1): CR47CR51.

20. Olson S, Seidel Jr G. Culture of in vitro-produced bovine embryos with vitamin $\mathrm{E}$ improves development in vitro and after transfer to recipients. Biology of Reproduction. 2000; 62(2): 248-52.

21. Peng Y, Kwok K, Yang P-H, Ng SS, Liu J, Wong O, et al. Ascorbic acid inhibits ROS production, NF- $囚 \mathrm{~B}$ activation and prevents ethanol-induced growth retardation and microencephaly. Neuropharmacology. 2005; 48(3): 426-34.

22. Burton GJ, Watson AL, Hempstock J, Skepper JN, Jauniaux E. Uterine glands provide histiotrophic nutrition for the human fetus during the first trimester of pregnancy. The Journal of Clinical Endocrinology \& Metabolism. 2002; 87(6): 2954-59.

23. Burton GJ, Jauniaux E. Placental oxidative stress: from miscarriage to preeclampsia. Journal of the Society for Gynecologic Investigation. 2004; 11(6): 342-52.

24. Sane A, Chokshi SA, Mishra V, Barad D, Shah V, Nagpal S. Serum lipoperoxides in induced and spontaneous abortions. Gynecologic and obstetric investigation. 1991; 31(3): 172-75

25. Sugino N, Nakata M, Kashida S, Karube A, Takiguchi S, Kato H. Decreased superoxide dismutase expression and increased concentrations of lipid peroxide and prostaglandin $\mathrm{F} 2 \mathrm{X}$ in the decidua of failed pregnancy. Molecular human reproduction. 2000; 6(7): 642-47.

26. MARGOLIN Y, ATEN RF, BEHRMAN HR. Antigonadotropic and antisteroidogenic actions of peroxide in rat granulosa cells. Endocrinology. 1990; 127(1): 245-50.

27. Umaoka Y, Noda Y, Narimoto K, Mori T. Effects of oxygen toxicity on early development of mouse embryos. Molecular reproduction and development. 1992; 31(1): 28-33.

Received: 22 March 2021

Accepted: 21 May 2021 